Cahiers Charlevoix

Cahiers Charlevoix

Études franco-ontariennes

\title{
Aux origines de l’identité franco-ontarienne
}

\section{Gaétan Gervais}

Volume 1, 1995

URI : https://id.erudit.org/iderudit/1039462ar

DOI : https://doi.org/10.7202/1039462ar

Aller au sommaire du numéro

\section{Éditeur(s)}

Société Charlevoix

Presses de l'Université d'Ottawa

ISSN

1203-4371 (imprimé)

2371-6878 (numérique)

Découvrir la revue

Citer cet article

Gervais, G. (1995). Aux origines de l'identité franco-ontarienne. Cahiers

Charlevoix, 1, 125-168. https://doi.org/10.7202/1039462ar
Résumé de l'article

L'historien Gaétan Gervais, professeur à l'Université Laurentienne, analyse le problème de l'identité franco-ontarienne d'un point de vue contemporain. Il voit dans l'éclatement du Canada français, provoqué par la Révolution tranquille, la source du malaise identitaire des élites ontaroises actuelles. Exclus par un Québec qui récupère comme québécois tout l'héritage naguère canadien-français, avec l'encouragement d'organismes nationaux - l'auteur montre du doigt la Société Radio-Canada, dite « la SRC », et le Secrétariat d’État (Patrimoine canadien) - qui opposent les Québécois aux «francophones » canadiens, les Franco-Ontariens s'ontarianisent : le déplacement de leurs centres d'activités vers Sudbury et Toronto est en cela significatif. 


\section{AUX ORIGINES DE L'IDENTITÉ FRANCO-ONTARIENNE}

Gaétan Gervais

Département d'histoire

Université Laurentienne, Sudbury

Cahiers Charlevoix 1, 1995, pp. 125-168. 
SOMMAIRE

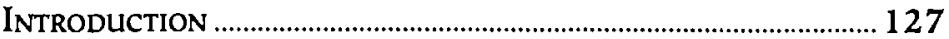

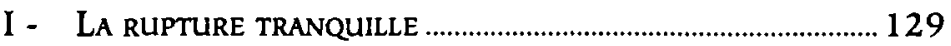

II - L'ONTARIo fRANÇAIS EN AMERIQUE fRANÇAISE: LE LONG TERME.

III - LA NOUVELLE SITUATION DE LA MINORITÉ FRANCO-ONTARIENNE Au CANADA (1969-1995) .................. 142

IV - LE QUESTIONNEMENT SUR L'IDENTITÉ FRANCO-ONTARIENNE DEPUIS VINGT ANS ................................. 146

V - LA NOUVELLE diRECTION EN ONTARIO FRANÇAIS ................... 160

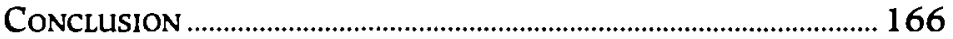




\section{AUX ORIGINES DE L'IDENTITÉ FRANCO- ONTARIENNE}

\section{INTRODUCTION}

Vu du Ciel, l'Ontario français peut paraître un épiphénomène. Rien ne singularise assez cette communauté pour l'élever au rang de "société distincte», même pas assez pour la faire accéder au modeste rang de «minorité officielle». En effet, tout dans l'histoire de la communauté franco-ontarienne semble s'expliquer soit par le cadre culturel que constitue l'Amérique française, notamment ses rapports avec les majorités anglaises du continent, soit par l'encadrement économique nord-américain qui a toujours déterminé les conditions du développement matériel de la communauté. C'est déjà entrevoir que les FrancoOntariens, culturellement ${ }^{1}$ et économiquement ${ }^{2}$

\footnotetext{
"Ce thème de la marginalisation "littéraire" et culturelle est bien exposé dans François Paré, Les Littératures de l'exiguité ([Hearst], Le Nordir, «Essais», 1992, 175 p.).

${ }^{2}$ Sur la situation économique des Franco-Ontariens, on consultera le travail un peu vieilli d'Yvan Allaire et de Jean-Marie Toulouse, Situation socio-économique [et satisfaction] des chefs de ménage francoontariens ( 2 volumes, Ottawa, Association canadienne-française de l'Ontario, 1973. Volume I: [xv]-vil-182 + A150 p. Volume II: [xx]-ii-
} 
marginalisés, subissent les événements bien plus qu'ils ne leur commandent.

Il est pourtant devenu courant de parler de «l'identité franco-ontarienne ${ }^{3}$. Certains, plus audacieux, parlent même de la "culture franco-ontarienne», quand ce n'est pas carrément du «peuple franco-

234 + A98 p.); Ken Choquette, La Situation économique des FrancoOntariens, Éclairage... et lueurs d'espoir... un rapport de fin de mandat. Présenté a l'Association canadienne-française de l'Ontario et au Ministère des Affaires intergouvernementales du Québec ([Ottawa, Association canadienne-française de l'Ontario], novembre 1980, [iv]-35 p. + 5 annexes $(1$ p. +16 p. +2 p. $+[11 i]-14$ p. +9 p. $])$; Jacques Grimard et Gaétan Vallières, Travailleurs et gens d'affaires canadiens-français en Ontario (Montréal, Études Vivantes, «L'Ontario français», 1986, 231 p.); Fernand Ouellet, "L'Évolution de la présence francophone en Ontario: une perspective économique et sociale», dans C. Jaenen (dir.), Les Franco-Ontariens ([Ottawa], Ontario Historical Studies Series / Presses de l'Université d'Ottawa, [c1993], vill-443 p.), pp. 127-199); Gilles Paquet, «Pour une socio-économie franco-ontarienne», dans Les Voies de l'avenir franco-ontarien. Actes du Colloque de l'Association canadienne-française de l'Ontario (Ottawa, Assoclation canadiennefrançaise de l'Ontario, 1988).

${ }^{3}$ On peut en volr une preuve récente dans l'ouvrage publié sous la direction de Jocelyn Létourneau (avec la collaboration de Roger Bernard), La Question identitaire au Canada francophone. Récits, parcours, enjeux, hors-lieux (Sainte-Foy, Presses de l'Université Laval, "Culture française d'Amérique», 1994, xvi-292 p.). Cet ouvrage contient deux articles traitant de la question de «l'identité francoontarienne»: d'abord celui de François Paré, «L'Institution littéraire franco-ontarienne et son rapport a la construction identitaire des FrancoOntariens» (pp. 45-62), puis celui de Roger Bernard, «Du social à I'individuel: naissance d'une identité bilingue» (pp. 155-163). Vient aussi de paraître, sous la direction de Lucle Hotte, La Problématique de l'identité dans la littérature francophone du Canada et d'ailleurs. Actes du colloque organisé par les étudiants du département des lettres françaises de l'Université d'Ottawa les 12 et 13 mai 1994 ([Ottawa, Le Nordir, c1994], 152 p.), où l'on trouvera notamment les communications de Carine Bourget, "La Représentation de l'identité dans le théâtre canadien francophone de 1968 à 1980" (pp. 20-28), de Katherine Lagrandeur, «L'Identitaire polyphonique. Almanda WalkerMarchand (1868-1949): une féministe franco-ontarienne de première heure» (pp. 39-45) et d'Élisabeth Laserre, «Identité et minorité dans l'écriture de Patrice Desblens" (pp. 73-80). 
ontarien». Mais des réalités aussi profondes qu'une nouvelle culture ou une nouvelle identité ont-elles pu surgir soudainement, en une seule génération? On chercherait longtemps, dans les écrits ou les discours antérieurs à 1960, avant de trouver des expressions comme «identité franco-ontarienne" ou "culture franco-ontarienne».

\section{LA RUPTURE TRANQUILLE}

À l'origine de ce questionnement, au fait, se trouvent les bouleversements culturels causés par l'éclatement du Canada français, survenu durant les années soixante. À cette époque de la "Révolution tranquille» au Québec (1960-1966) et de la Commission royale d'enquête sur le bilinguisme et le biculturalisme (Laurendeau-Dunton) à travers tout le Canada (19631969), les principaux porte-parole de la communauté canadienne-française de l'Ontario appuyèrent fortement les revendications qui s'élevèrent pour réclamer l'égalité des deux peuples fondateurs du Canada, c'est-à-dire le Canada français et le Canada anglais. D'un bout à l'autre du pays, de l'Acadie au Québec et à l'Ouest, dans les divers groupes français, les chefs nationalistes endossèrent les objectifs d'égalité, de modernisation, de libération et d'épanouissement culturel. Mais cette explosion culturelle était appelée à prendre des formes spécifiques: au Québec d'abord, avec la montée du néo-nationalisme, mais aussi en Acadie, où se produisit une grande renaissance culturelle, et bientôt dans plusieurs autres provinces canadiennes. Tous ces mouvements, par contre, ne marchaient pas aux battements d'un même tambour.

Deux moments forts ont marqué la rupture. La première grande manifestation de division s'exprima de 
façon claire, en 1965, lors de l'éclatement de l'Ordre de Jacques-Cartier, naufragé sur les bas-fonds de querelles opposant les néo-nationalistes québécois aux nationalistes canadiens-français des autres provinces ${ }^{4}$. Quand on sait l'importance du rôle que cet organisme a joué dans l'organisation des minorités françaises, notamment en Ontario français où l'Ordre avait été fondé en 1926, cette dissolution marquait une étape décisive. Mais c'est en 1969 que, de façon publique cette fois, la division fut consommée quand les États-Généraux du Canada français, dans leur majorité, optèrent en faveur d'un nationalisme territorial basé non plus sur le Canada, mais sur le Québec seulement. C'était le rejet du fédéralisme canadien, mais aussi du projet du Canada français. Au Québec même, ces divisions se répercutèrent dans le parti libéral provincial qui, en 1967, se scinda pour engendrer le mouvement souveraineté-association, à l'origine du "parti québécois».

Une des premières conséquences de cette rupture fut la substitution systématique du terme «québécois» à tout ce qui, jusqu'alors, avait porté le qualificatif de «canadien-français». Or cette "québécisation" de la culture canadienne-française, ajoutée au rejet d'un fédéralisme politique canadien qui commençait enfin, en 1969, à redresser certaines injustices historiques commises contre toutes les minorités françaises du Canada, ne constituait pas une évolution acceptable, ni même viable, pour les groupes minoritaires français. Car la spécificité exclut: determinatio est negatio (Leibnitz). Là se trouve l'origine d'un éloi-

\footnotetext{
${ }^{4}$ Voir G.-Raymond Laliberté, Une Société secrète: l'Ordre de Jacques Cartier (Montréal, Hurtubise HMH, "L'homme dans la société", [c1 1983], 395 p.).
} 
gnement que Pierre de Bellefeuille évoquait récemment en parlant des "frères divisés" ${ }^{5}$. C'est ainsi que les sympathies communes du départ s'estompèrent durant les années soixante-dix, notamment avec la montée irrépressible du néo-nationalisme québécois et sa fixation absolue sur l'indépendance politique du Québec et sur la recherche de la "terre promise» ${ }^{6}$.

L'éclatement du Canada français a fait naître deux ressentiments profonds chez la minorité francoontarienne, et sans doute chez les autres minorités françaises du pays aussi: l'exclusion (les indépendantistes étant désormais les seuls purs) et la dépossession (la "québécisation" de la culture canadienne-française, processus culturel par lequel la "culture québécoise" s'appropria tout le bien culturel commun). Beaucoup de Franco-Ontariens eurent le fâcheux sentiment d'être expulsés de la maison familiale. Le "choc culturel» fut d'autant plus difficile, pour l'Ontario français, que le quart de la population franco-ontarienne actuelle est né au Québec ${ }^{7}$ et que le gouvernement du Québec, historiquement, fut le seul gouvernement à soutenir indéfectiblement les droits linguistiques des minorités françaises partout au Canada; les parents francoalbertains savent aujourd'hui qu'il n'en va plus ainsi.

\footnotetext{
${ }^{5}$ Pierre de Bellefeuille. "Les Frères divisés", dans L'Action Nationale 83(10), décembre 1993, pp. 1432-1439. Dans une communication en Saskatchewan, Fernand Harvey a aussi abordé cette question, "Le Québec et le Canada français. Histoire d'une déchirure" (Communication présentée le 23 octobre 1992 au $12^{\circ}$ Colloque annuel du Centre d'études franco-canadiennes (CEFCO) tenu à l'Institut de formation linguistique, Université de Régina, Saskatchewan, 23 octobre 1992, 24 pages (polycoplé).

6 Yves Couture, La Terre promise. L'Absolu politique dans le nationalisme québécois, [Montréal], Liber, [c1994], 222 p.

${ }^{7}$ Selon le Recensement de 1991, 24,7\% des Franco-Ontariens (123 555 personnes) étaient nés au Québec et 3,9\% (19 380 personnes) étaient nés à l'extérieur du Canada.
} 
Il est de même révolu le temps où les nationalistes de Montréal parlaient encore de leurs "frères" de l'Ontario, avant d'en faire des "cousins" et, plus récemment, des «amis». C'est un éloignement dont rendent bien compte les déclarations affligeantes comme les "dead ducks» de René Lévesque ou les "cadavres encore chauds" d'Yves Beauchemin.

Au clair, l'origine de la "crise d'identité» de l'Ontario français résulte de facteurs exogènes. Le nouveau questionnement fut le résultat d'abord de l'éclatement du Canada français durant les années soixante, mais aussi de l'aliénation croissante causée par la politique de «québécisation» systématique de la culture canadienne-française. La minorité francoontarienne se trouvait, à la fin du compte, doublement marginalisée: d'abord du point de vue politique par rapport à son gouvernement provincial, puis du point de vue culturel par rapport au "projet québécois». Les «Canadiens-Français de l'Ontario» furent ainsi conduits, un peu sans le savoir, dans les eaux troubles des définitions d'identité, questions difficiles à résoudre entre toutes. Ce sont les universitaires et les artistes qui, les premiers, se sont lancés dans cet exercice.

\section{II - L'ONTARIo français EN AMÉrique françaISE: LE LONG TERME}

Dans le long terme, séculaire, et à l'échelle du continent, la problématique de «l'identité francoontarienne" ne répond pas à un caprice, mais à des transformations politiques profondes. L'Empire français, qui fut à l'origine de tous les foyers de peuplement français sur le continent, se constitua aux XVII ${ }^{e}$ et XVIII ${ }^{e}$ siècles, au temps où s'établissait 
un système mondial d'échange et de commerce. C'est le début du monde plein, marqué, entre autres, par la mondialisation des échanges, l'établissement de réseaux commerciaux planétaires et l'implantation en Amérique de populations européennes, phénomènes bien étudiés par Fernand Braudel et Immanuel Wallerstein. Dans un premier temps, du XVI ${ }^{\mathbf{e}}$ au XVIII' siècle, l'Amérique du Nord fut départagée entre les Espagnols au sud, les Anglais sur la côte atlantique, enfin les Français sur les Grands-Lacs et dans les deux énormes vallées du Saint-Laurent et du Mississipi. L'Amérique française recouvrait une bonne partie des territoires qui forment aujourd'hui le Canada: l'Acadie, le Saint-Laurent (alors appelé le Canada), les Pays-d'en-Haut (les Grands-Lacs), la Mer de l'Ouest (les territoires à l'ouest du lac Supérieur) et, brièvement, même la baie d'Hudson. Mal défendu et peu peuplé, l'Empire français s'effondra en 1760.

Mais la Conquête anglaise, dont les effets, depuis Lionel Groulx, ont été tant discutés en historiographie canadienne-française ${ }^{8}$ par Maurice Séguin, Guy Frégault et Michel Brunet, ne fut pas seulement une catastrophe pour les Français du Canada, elle le fut aussi pour les Britanniques eux-mêmes. En fait, cet événement enclencha sur le continent une période d'instabilité qui dura un demi-siècle. La première crise, dans la poussière de l'effondrement de l'Empire français, fut la dislocation de l'Empire britannique lui-même. Après le traité de Paris (1763), les Britanniques, qui contrôlaient toute la partie septentrionale du continent, furent bientôt contestés dans leurs

${ }^{8}$ Sur l'école historlographique néo-nationaliste, voir Jean Lamarre, Le Devenir de la nation québécoise selon Maurice Séguin, Guy Frégault et Michel Brunet 1944-1969, [Sillery], Septentrion, [c 1993], 564 p. 
Treize Colonies elles-mêmes qui, libérées de la menace française, déclarèrent leur indépendance (1776). Parmi les lois britanniques jugées «intolérables» par les colonies, se trouvait l'Acte de Québec (1774) qui, non seulement reconnaissait le droit civil français et le droit de pratiquer la religion catholique, mais agrandissait les frontières de la "province de Québec» pour qu'elles englobent la région des Grands-Lacs. Au terme de la Guerre de l'Indépendance, les États-Unis acquéraient par le traité de Versailles (1783) leur indépendance et une frontière coupant en deux le bassin des Grands-Lacs. Les Britanniques mirent treize ans avant d'évacuer les postes de l'Ouest (Oswego, Détroit, Michillimackinac), ce qu'ils ne firent finalement qu'en 1796 . Enfin, on peut voir dans la Guerre de 1812 (1812-1814), entre les États-Unis et la Grande-Bretagne, le dernier épisode nord-américain de cet affrontement.

Cette transformation de la carte de l'Amérique du Nord répondait à des mutations encore plus profondes en Europe. La "révolution industrielle», dans le dernier tiers du XVIII ${ }^{e}$ siècle, puis la Révolution française (1789-1799), secouèrent le continent européen sur ses bases, ces chambardements faisant partie de ce que R. R. Palmer a appelé la "révolution atlantique». L'Europe s'engageait non seulement sur les voies de l'industrialisation, mais aussi du libéralisme, du nationalisme et de la démocratie. La Rébellion de 1837 , dans les deux Canadas, constitua un écho nordaméricain des révolutions libérales de l'Europe, alors que l'expansion des exportations de matières premières démontrait l'intégration de l'économie canadienne à l'économie mondiale, dominée, au XIX siècle, justement par la Grande-Bretagne. 
À la suite de cette dislocation, deux sphères politiques, toutes deux d'origine anglaise, se partagèrent la partie septentrionale du continent: les États-Unis d'une part, et, d'autre part, les colonies britanniques, celles-ci faisant partie de ce qu'on a appelé le "deuxième empire britannique». Aux États-Unis, le sort des populations françaises, notamment les Cadiens de la Louisiane, en anglais "Cajuns", fut déplorable. La situation dans les colonies anglaises ne fut guère meilleure, sauf au Canada où le poids des nombres empêcha la réalisation des politiques assimilationnistes que les gouvernements du temps tenaient facilement pour des projets de civilisation.

Ce deuxième empire britannique était appelé, sur le continent nord-américain, à se constituer en une seule puissance politique: le Canada. Le projet d'union, repris à différentes époques, se réalisa, concrètement, dans la Confédération canadienne de 1867. En fait, entre 1867 et 1873 , toutes les terres britanniques (sauf Terre-Neuve), furent admises dans la Confédération, y compris les immenses territoires de la Compagnie de la baie d'Hudson. Dans chacune de ces colonies, des populations françaises subsistaient ou s'implantaient: en Acadie, dans les différentes régions du Québec, en Ontario et dans l'Ouest du pays.

Ainsi, les colonies britanniques évoluaient séparément, mais leur avenir, tant politique qu'économique, convergeait. Mais qu'allaient devenir les populations françaises éparpillées sur le continent et qui formaient autant de vestiges humains de l'empire français? Le sort linguistique de tous ces groupes français n'était pas évident au $\mathrm{XIX}^{\mathrm{e}}$ siècle car plusieurs croyaient qu'ils suivraient le chemin de l'assimilation, 
comme aux États-Unis. Les desseins d'assimilation ont été souvent décrits, en passant par ceux de l'Institution Royale et de lord Durham9. Alors qu'en Louisiane, l'usage du français avait beaucoup décliné dès la fin du siècle dernier, sous les pressions réductrices de ce qu'on appelait alors «l'idée américaine", dans les colonies britanniques, des conditions différentes de survie prévalurent. Mais le facteur déterminant de la survie linguistique du Canada français, ce fut le poids démographique des Canadiens[Français] qui, malgré une immigration massive, restèrent majoritaires au Canada central jusqu'au milieu du XIX ${ }^{e}$ siècle. Après, la population française garda toujours le nombre critique qui permit la survie de ses institutions.

Une grande idée rassemblait toutes ces populations françaises: former une nation catholique et française. Cette idéologie ne fut pas seulement diffusée par toutes les élites, mais surtout par les communautés religieuses qui furent, à l'échelle du Canada, la cheville ouvrière du système d'enseignement. La paroisse et l'école furent, dans les groupes minoritaires comme l'Ontario français, des piliers extrêmement importants, d'autant plus que l'inévitable processus de minorisation menaçait sans cesse leur existence. Il n'est pas inutile de rappeler que le gouvernement fédéral attendit l'année 1969 avant d'établir une po-

\footnotetext{
${ }^{9}$ Voir J.-L. Gilles LeVasseur. Le Statut juridique du français en Ontario. Tome premier: La législation et la jurisprudence provinciales ([Ottawa], Presses de l'Université d'Ottawa, 1993, xxiv-272 p.), mais aussi Michel Bastarache, André Braën, Emmanuel Didier et Pierre Foucher. Les Droits linguistiques au Canada (Montréal, Éditions Yvon Blais, [c1986], xxv-576 p.) et Guy Bouthillier et Jean Meynaud, Le Choc des langues au Québec 1760-1970 (Montréal, Presses de l'université du Québec, 1972 , xiv-768 p.) qui prêsente, après une bonne introduction, une collection de 119 documents.
} 
litique de bilinguisme et qu'en attendant, les populations françaises du pays souffrirent beaucoup des divers projets d'assimilation qui hantèrent tous les gouvernements anglais du pays. En Ontario, ce dessein s'exprima avec le plus de clarté lors du Règlement XVII (1912-1927). Ce conflit fait partie d'une longue liste d'affrontements qui jalonnent l'histoire des relations anglo-françaises au Canada: le conflit des écoles du Nouveau-Brunswick (1871), la pendaison de Riel en Saskatchewan (1885), la question des écoles du Manitoba (1890-1897), la guerre des Boers (1899), les écoles du Nord-Ouest (1905), le Règlement XVII en Ontario (1912-1927), les crises de la conscription (1917-1918, puis 1942-1944).

Pourtant, les Canadiens-Français ${ }^{10}$, surtout au XX ${ }^{\mathrm{e}}$ siècle, prétendaient former l'un des deux peuples fondateurs de la Confédération, ce qui devait, à leurs yeux, garantir leurs droits à la langue et à la culture françaises partout au pays. Au fait, après 1867 , les populations d'origine française partagèrent, au sein

\footnotetext{
${ }^{10}$ Le nom Canadien-Français s'est écrit de différentes manières depuis un siècle et demi: Canadien-Français, Canadien-français, Canadien français. Il y aurait done des raisons historiques pour justifier Canadien-Français. Mais on doit aussi invoquer des raisons grammaticales puisque le trait d'union entre Canadien et Français indique l'unité lexicale du terme Canadien-Français. Pour la même raison qu'un "sourd-muet" n'est pas un "sourd muet», un "CanadienFrançais" n'est pas un "Canadien français». Une discussion de cette question se trouve dans une longue note au début de l'article suivant: Gaétan Gervais, «De Sagard à Lemieux: la contribution des religieux à la connaissance de l'Ontario français», dans Jean-Pierre Pichette (s.d.), L'CEuvre de Germain Lemieux, s.j. Bilan de l'ethnologie en Ontario français. Actes du colloque tenu d l'Université de Sudbury les 31 octobre, $1^{\text {er }}$ et 2 novembre 1991, Sudbury, Prise de parole / Centre francoontarien de folklore, "Ancrages", 1993, pp. 57-58; voir aussi Gaétan Gervais, "Réflexion. Canadien-Français ou Franco-Ontarien?", dans Fleur de trille. Regroupement des organismes du patrimoine francoontarien, 10, décembre 1993, pp. 3-5.
} 
de la Confédération, un sort commun. La Confédération de 1867 , en réunissant toutes les colonies et tous les territoires que l'empire britannique possédait en Amérique septentrionale, regroupa, la première fois depuis 1760 , les foyers de peuplement français de l'Acadie, du Saint-Laurent et du Nord-Ouest sous un même gouvernement. À compter de ce moment, la population française du Canada connut un destin commun et une solidarité se développa entre les communautés françaises du pays, en commençant par les Canadiens-Français qui formaient la majorité dans la province de Québec.

Ainsi s'articula, aux $\mathrm{XIX}^{\mathrm{e}}$ et $\mathrm{XX}^{\mathrm{e}}$ siècles, le grand projet social du Canada français, dans le même cadre que la Confédération canadienne, son pendant politique. L'idée de Canada français se confond avec l'idéologie ultramontaine qui servit à le définir et lui apporta, pendant plus d'un siècle, le support idéologique pour durer. Le nationalisme canadienfrançais a donc pris la couleur de ces idées conservatrices qui s'imposèrent d'un bout à l'autre du pays. L'élaboration de cette "identité canadiennefrançaise» dépendit de plusieurs facteurs, en commençant par le renouveau religieux des années 1840 , les efforts missionnaires entrepris à l'échelle du continent et la fusion idéologique de l'ultramontanisme et du nationalisme, comme on le vit chez l'évêque trifluvien Louis Laflèche ou chez Mgr L.-A. Paquet. Mentionnons encore les nombreux plans de colonisation et de peuplement qui animèrent ces élites. Mais surtout, notons bien les tentatives d'encadrement systématique de la vie sociale, religieuse et culturelle des communautés de langue française. Ces efforts trouvent une expression achevée dans la diffusion des mouvements d'action catholique, agis- 
sant selon l'idéologie tridentine qui vise à encadrer dans des organisations tous les aspects de la vie du croyant. Tous ces facteurs se fusionnèrent pour supporter un projet politique (un Canada indépendant de la Grande-Bretagne, la reconnaissance des deux peuples fondateurs de la Confédération canadienne), un projet social (le maintien des valeurs traditionnelles et catholiques) et un projet culturel (la «culture canadienne-française»), le tout qu'on aurait facilement pu regrouper sous le vocable de «l'identité canadienne-française».

Pour caricaturer, en parlant du Canada français entre 1840 et 1967 , on pourrait dire que ses idées sont ultramontaines, que son encadrement est cléri$c a l$, que son projet politique a été l'indépendance du Canada, que sa vision se fondait sur un projet canadien reconnaissant l'égalité des deux peuples fondateurs, que ses troupes de choc furent les communautés religieuses, surtout après leur "canadianisation" au tournant du $\mathrm{XX}^{\mathrm{e}}$ siècle. Après leur implantation à travers le Canada français, celles-ci dirigèrent partout le réseau institutionnel canadien-français comprenant écoles, collèges, hôpitaux, asiles, hospices, orphelinats, journaux, centres culturels et un important réseau d'associations de toute sorte. Toute une vision du monde, bien plus grande que les frontières provinciales, s'exprimait dans ces démarches, une vision diffusée par les élites, tant laïques que cléricales, vision du monde qui concevait le peuple canadien-français comme une nation catholique et française, appelée à jouer un rôle central dans la conversion du continent au catholicisme. La langue et la religion devenaient ainsi des frères siamois, jumelés pour appuyer le zèle messianique qui prit la forme tantôt de mouvements missionnaires très forts, 
tantôt d'un agriculturisme militant à l'origine de puissants mouvements de colonisation agricole et d'implantation de colonies rurales à travers le Canada. Mais n'insistons pas sur ces traits qui ont souvent été décrits.

Ces faits expliquent la naissance de l'Ontario français et la mise en place de ses principales institutions. La présence française sur le territoire qui forme aujourd'hui l'Ontario est ancienne et remonte à l'arrivée, en 1610, du coureur de bois Étienne Brûlé, envoyé et bientôt suivi par Samuel de Champlain qui fit deux voyages en Ontario, y compris un séjour de plusieurs mois en Huronie, au sud de la baie Georgienne, en 1615-1616. Des centaines de missionnaires, de militaires et de marchands de fourrure français ont aussi visité cette région, mais peu restèrent, en dehors de la population française établie à l'Assomption dès les années 1740 et de quelques voyageurs abandonnés ici et là.

Le principal peuplement canadien-français en Ontario se produisit au XIX ${ }^{\mathrm{e}}$ siècle, enclenché par le commerce de la fourrure finissant (les «voyageurs»), mais surtout par l'industrie du bois qui attira des milliers de «bûcherons" qui se tranformèrent souvent en colons, amenant ici femme et enfants. L'Ontario français, au XIX ${ }^{\mathrm{e}}$ siècle, n'était qu'une région nouvelle de peuplement, au même titre que les Laurentides, l'Estrie, le Lac-Saint-Jean, le Manitoba ou le Madawaska au nord du Nouveau-Brunswick. Partout, les gouvernements et le clergé firent du zèle pour implanter des colons sur les terres incultes, motivés par un désir d'éviter l'émigration vers les villes, surtout les villes américaines. Quant au clergé canadien-français, il craignait en plus que l'assi- 
milation ne conduise à la protestantisation, ce qui montre bien que la colonisation fut plus qu'un projet social et politique, ce fut un projet religieux.

C'est dans ce cadre du Canada français que les principaux foyers de peuplement franco-ontariens se développèrent au XIX ${ }^{e}$ siècle, dans les comtés de l'Est, en Huronie, dans Essex-Kent, plus tard dans le nord de l'Ontario. Les activités économiques (la coupe du bois, l'agriculture, les mines) attirèrent les colons canadiens-français en Ontario, mais le clergé se soucia dès le début d'encadrer cette population. Comme on croyait que "qui perd sa langue perd sa foi», il allait de soi qu'il fallait protéger à la fois la langue et la religion, préférablement en milieu rural. L'immigration, toutefois, se produisit en direction des villes ontariennes, les Franco-Ontariens s'urbanisant au même rythme, ou presque, que les autres Ontariens.

Dans une province anglaise et protestante comme l'Ontario, l'opposition à la communauté française ne vint pas seulement des pouvoirs politiques provinciaux, mais aussi du clergé irlandais qui, lui, souscrivait à «l'idée américaine», c'est-à-dire à la promotion de l'anglicisation. Écartées du pouvoir politique et économique, et ne jouissant d'aucune reconnaissance officielle, les élites de l'Ontario français se replièrent sur les seules institutions où les Canadiens-Français de l'Ontario pouvaient espérer conserver leur langue et leur foi, celles qui devinrent capitales dans le maintien de la langue, de la culture et de la religion: la paroisse et l'école. Ces deux institutions ont joué un rôle de suppléance en Ontario français, là précisément où le clergé a pu fournir l'encadrement nécessaire en personnel et en ressources.

L'Ontario français était alors la partie ontarienne 
du Canada français, comme on le vit par sa participation lors des grands congrès de la langue française tenus à Québec en 1912, en 1937 et en 1952. Mais lors des États-Généraux du Canada français, tenus à Montréal en 1967-1969, une nouvelle conjoncture aboutit à la «rupture tranquille».

\section{La NOUVELLE SITUATION DE LA MINORITÉ FRANCO- ontarienNe au Canada (1969-1995)}

Aujourd'hui, l'Ontario français a cessé d'être la partie ontarienne du Canada français, pour devenir la partie française de l'Ontario. Cette mutation, engendrée directement par la disparition de l'identité canadienne-française dans les années soixante, s'exprime, depuis un quart de siècle, par «l'ontarianisation" de la minorité franco-ontarienne et par le changement de son leadership. C'est dans cette évolution qu'on doit chercher les sources de «l'identité franco-ontarienne». Parmi les facteurs qui ont le plus favorisé cette "ontarianisation", il faut citer, d'une part, le désengagement des grandes institutions canadiennes-françaises basées surtout dans la province de Québec, c'est-à-dire l'abandon presque complet de leurs relations privilégiées, entretenues depuis longtemps, avec les minorités françaises du pays et, d'autre part, la présence nouvelle du gouvernement fédéral, voire des gouvernements provinciaux, dans le développement de leur minorité linguistique respective. Depuis vingt ans et malgré des lacunes béantes et des négligences scandaleuses dans la plupart des provinces anglaises, le sort des minorités françaises au Canada s'est amélioré.

Le redressement de la situation chez les minorités commença bien lentement, malgré les débats tapa- 
geurs qui entourèrent les travaux de la Commission Laurendeau-Dunton sur le bilinguisme et le biculturalisme (1963-1969). Quant aux ridicules sauts de puce que les gouvernements provinciaux anglais consentirent parfois à faire, ils ne pouvaient constituer une réponse adéquate pour corriger, au Québec et ailleurs, des injustices historiques commises contre les Canadiens-Français depuis le début de la Confédération, injustices que certains politiciens s'obstinent, aujourd'hui encore, à nier. Une première conséquence de la division qui éloignait sans cesse le Québec des groupes minoritaires français, c'est que les minorités se tournèrent définitivement vers le gouvernement fédéral pour obtenir justice. De nouvelles politiques linguistiques, à compter de 1969 , et la Charte des droits et libertés, en 1982, aidèrent grandement le développement des groupes en situation minoritaire au pays, tels les Franco-Ontariens.

En Ontario, trois dates marquent des moments forts de cette transformation: 1969 (la loi fédérale des langues officielles), 1982 (le rapatriement de la constitution, enrichie d'une nouvelle Charte des droits et libertés dont l'article 23 garantit certains droits scolaires), 1986 (la loi ontarienne des services en français). Mais le chemin parcouru ne doit pas faire oublier tout ce qui reste à faire; en particulier, ne nions pas les très graves problèmes de l'assimilation, récemment analysés par Roger Bernard ${ }^{11}$, et que la minorité franco-ontarienne continue de combattre avec l'énergie du désespoir.

\footnotetext{
1 Voir Roger Bernard, Un avenir incertain. Comportements linguistiques et conscience culturelle des jeunes Canadiens français ([Ottawa], Fédération des jeunes Canadiens françals, "Vision d'avenir» III, [c1991], 280 p.).
} 
Paradoxalement, les minorités françaises du Canada ont profité de l'agitation séparatiste survenue au Québec. Elle a servi à sensibiliser certains politiciens provinciaux à l'iniquité du traitement fait à leur minorité française. Quand, il y a trente ans, le gouvernement fédéral commença à se préoccuper davantage de l'égalité des deux groupes linguistiques du pays, après un siècle d'inaction et malgré des cicatrices profondes, les minorités furent très heureuses des politiques d'Ottawa et de l'évolution, combien lente, des attitudes provinciales.

Que les politiques fédérales d'aide aux minorités françaises aient comporté leur part de "manœuvres»" ${ }^{12}$ pour confondre le néo-nationalisme québécois, c'est une chose qu'on peut admettre facilement. Disons toutefois qu'Ottawa n'a fait qu'occuper un terrain laissé vacant par les élites traditionnelles de Montréal et de Québec qui, renonçant au rôle traditionnel de direction et d'appui à l'ensemble des combats du Canada français, se repliaient sur la forteresseQuébec. Ces élites, durant les années soixante, ont abandonné leur leadership au Canada français, créant le "hiatus historique»" ${ }^{13}$ où le Québec noua des liens avec la France, l'Europe, l'Afrique et l'Asie, mais coupa presque tous ses liens avec les minorités françaises du Canada. Les élites néo-nationalistes ayant abandonné leur leadership, il était inévitable que les minorités se tournent à la fois vers Ottawa et vers leur gouvernement provincial respectif où elles ont cherché, et heureusement trouvé, de nouveaux ap-

\footnotetext{
${ }^{12}$ Pierre de Bellefeuille, "Les Frères divisés», dans L'Action Nationale 83(10), décembre 1993, p. 1436.

${ }^{13}$ Roméo Paquette, «Le Québec francophone et les communautés de langue française», dans L'Action Nationale 83(8), octobre 1993 , p. 1124.
} 
puis. Car, en politique, ce ne sont pas les motivations qui comptent, mais les résultats.

Que reste-t-il de l'important réseau religieux, culturel et social qui unissait naguère toutes les parties du Canada français, d'un bout à l'autre du pays? N'ont survécu à la tourmente que l'ACFAS (Association canadienne-française pour l'avancement des sciences), l'ACELF (Association canadienne d'éducation de langue française) et certaines relations privilégiées dans le secteur des caisses populaires.

Au niveau provincial, toutefois, reconnaissons que malgré l'ampleur de la crise, les provinces, sauf le Nouveau-Brunswick et l'Ontario, ont répondu avec timidité, parcimonie et incompréhension. Il faut bien comprendre que les provinces ont, dans leur champ de vision, un angle mort: les droits de leur minorité française. Les gouvernements provinciaux n'ont souvent avancé qu'à reculons, habituellement pour «apaiser le Québec». Ainsi, en Ontario, on a entendu un premier ministre provincial dire, à l'ouverture d'une école secondaire française, qu'il espérait que «cela plaira au Québec». Incapables d'élever le regard audessus des clôtures provinciales, beaucoup de politiciens provinciaux ont leur large part dans la crise constitutionnelle qui secoue le Canada depuis une génération. Leur manque de courage et leur insensibilité à la fois au sort de leur propre minorité française et au problème plus général de l'égalité des deux peuples fondateurs dans l'ensemble du Canada pèseront lourd dans le jugement qu'on portera sur leur gestion de la présente crise, car, en refusant l'égalité des deux peuples à l'échelle du pays, ils assuraient le maintien des profonds sentiments d'injustice qui empoisonnent le climat politique depuis 
trente ans et qui alimentent sans cesse les mouvements pour l'indépendance du Québec.

Toutefois, pour la minorité franco-ontarienne, il est maintenant évident que son développement passe désormais par Toronto, non plus par Québec ou Montréal. Longtemps minorité négligée et ignorée dans sa propre province, elle connaît depuis 1969 un début de redressement, difficile certes, et très lent, mais qui l'a déjà conduite à une reconnaissance partielle en 1986 et à l'acquisition de nouveaux droits scolaires, enfin à la mise sur pied d'un important réseau d'organisations culturelles et sociales. Il est évident que son sort, désormais, diverge de celui du Québec, quelle que soit l'issue des présents débats constitutionnels.

\section{IV - LE QUESTIONNEMENT SUR L'IDENTTIÉ FRANCO- ONTARIENNE DEPUIS VINGT ANS}

Cette nouvelle situation est à l'origine du questionnement qui se produit depuis deux décennies sur «l'identité franco-ontarienne». Il y a cinquante ans, Victor Barrette, rédacteur au journal Le Droit, publiait dans la "Collection franco-ontarienne" de la Société historique du Nouvel-Ontario, une brochure au titre clair: Moi franco-ontarien. Mes droits. Mes devoirs ${ }^{14}$. Barrette n'inventait rien, il réaffirmait des choses connues. Les Franco-Ontariens, ou les "Canadiens-Français de l'Ontario», avaient des droits, des devoirs et leur place au soleil ne faisait pas difficulté. En 1910, l'Association provinciale d'éducation avait tout naturellement mis le quali-

14 Victor Barrette, Moi franco-ontarien. Mes droits. Mes devoirs (Sudbury, Société historique du Nouvel-Ontario, «Collection francoontarienne» 2 , [1947], 32 p.). 
ficatif "canadien-français" dans son nom officiel, ce qu'elle garde encore aujourd'hui: Association canadienne-française de l'Ontario - ACFO.

Le passage des certitudes de 1960 , avec une identité canadienne-française bien ancrée, aux doutes des années soixante-dix, s'explique par la rupture culturelle survenue dans la décennie précédente. Au fait, il est facile d'imaginer que les "CanadiensFrançais de l'Ontario», laissés à eux-mêmes et après avoir lutté si longtemps pour maintenir leur langue, leur culture et leur religion, n'auraient pas spontanément senti le besoin de se trouver une nouvelle «identité». Comment une telle préoccupation aurait-elle pris naissance au sein d'une minorité privée de la moindre reconnaissance officielle, ne disposant que d'un réseau scolaire tronqué, souffrant de graves problèmes d'analphabétisme et de sous-scolarisation, ne produisant que très peu de professionnels, d'ailleurs recrutés au Québec? Par un simple examen des nombreuses questions débattues en congrès généraux annuels à l'Association canadienne-française de l'Ontario (ACFO) depuis vingt ans, on pourrait démontrer que le problème de l'identité n'a pas préoccupé grand monde. À y regarder de près, on peut facilement constater qu'en qualifiant de «francoontarien» tout ce que nos parents appelèrent «canadienfrançais de l'Ontario", on se reconnaît sans peine. Le questionnement est venu de l'extérieur, conçu dans la mouvance idéologique du néo-nationalisme québécois. En outre, c'est un problème qui ne se pose que chez les élites et les intellectuels. Pour les «Canadiens-français de l'Ontario», dont les deux tiers, aujourd'hui, sont nés en Ontario, les ancêtres sont venus de France, puis du Québec avant d'aboutir en 
Ontario; comme leurs parents, ils se disent indifféremment Canadiens-Français ou Franco-Ontariens.

Au début des années soixante-dix, un bouillonnement artistique se produisit à Sudbury, en bonne partie inspiré par certains événements culturels du Québec (la "Nuit de la poésie», tenue à Montréal, influença l'avènement de la «Nuit sur l'étang», créée à Sudbury en 1973 et appelée à un grand succès artistique). Un important mouvement de jeunes créateurs était lancé. Parmi les succès les plus durables de cette animation, outre la "Nuit sur l'étang", il faut surtout mentionner la création de la maison d'édition Prise de parole, au service, selon sa propre publicité, des "créateurs franco-ontariens" et "animatrice des arts littéraires chez les francophones de l'Ontario», le groupe du Théâtre du Nouvel-Ontario (TNO), enfin le groupe de CANO-Musique. Les jeunes ${ }^{15}$ et les artistes ${ }^{16}$ ont souvent été les plus militants dans l'affirmation de cette nouvelle identité francoontarienne. Lors de cette "patiente et fervente prise de conscience», selon les termes de Yolande Grisé, on lança d'abord le terme "Ontarois» en 1979. Le professeur Grisé proposa que les Franco-Ontariens adoptent ce nouveau nom d'Ontarois ${ }^{17}$. Mais cette

15 Jocelyne Beaulieu, "Être franco-ontarien», dans Clik 3, n' 14, octobre 1989, pp. 20-21; François-Pierre Gingras, «Identité: jeune, francophone minoritaire en Ontario», dans Francophonies d'Amérique 3, 1993, pp. 91-103.

${ }^{16}$ Micheline Piché, «Art visuel et éducation: pour que l'identité ontaroise prenne racine», dans Femmes d'action 16(5), juin-juillet 1987, p. 7 et p. 38. Le Collège Glendon a aussi tenu un colloque qui a abordé cette question: La Culture franco-ontarienne: traditions et réalités nouvelles. Franco-Ontarian culture: traditions and new perspectives. Actes du colloque / Conference proceedings 28, 29 octobre - October 1982. Préface de Gail Brandt et Suzanne Legault, [Toronto], Collège Glendon (York University), [1982], xv-79 p.

17 Yolande Grisé, "Ontarois: une prise de parole», dans Revue du 
création terminologique ne réussit guère que dans le cadre restreint de certains milieux artistiques, tant il est difficile de changer des habitudes de langage. Ainsi, même le "Contact ontarois", un rassemblement annuel des producteurs de spectacles, est organisé par le "Bureau franco-ontarien" (et non "ontarois») du Conseil des arts de l'Ontario, celui-ci créé en 1970.

Le mouvement se propagea ensuite dans les milieux universitaires. C'est précisément au cours des années 1970 que commencèrent les premières études universitaires touchant les Franco-Ontariens, le Centre franco-ontarien de folklore, à Sudbury (CFOF), et le Centre de recherche en civilisation canadienne-française (CRCCF), à l'université d'Ottawa, étant pionniers en cette matière, bientôt suivis par l'Institut franco-ontarien de Sudbury (IFO) ${ }^{18}$. Le premier regroupement de chercheurs commença, modestement, dans le cadre du Groupe interuniversitaire pour l'étude des Franco-Ontariens (GIÉFO). Depuis cette époque, un nombre croissant de travaux sur l'Ontario français a vu le jour ${ }^{19}$. Depuis une

Nouvel-Ontario 4, 1982, pp. 81-88. Pour une réponse en cinq points à cette proposition qui a "fait long feu», voir René Dionne, "Les FrancoOntariens: un appel à la fierté», Le Devoir, 15 juin 1984, p. 9.

${ }_{18}$ Pierre Savard, "Le Centre de recherche en civilisation canadiennefrançaise (CRCCF)», pp. 97-112 et Jean-Pierre Pichette, «Le Centre franco-ontarien de folklore et le Département de folklore de l'Université de Sudbury", pp. 113-128, dans René Dionne (dir.), Quatre siècles d'identité canadienne. Actes d'un colloque tenu au Centre de recherche en civilisation canadienne-française de l'Université d'Ottawa, le 23 octobre 1981, [...], Montréal, Éditions Bellarmin, 1983, 176 p. Voir aussi, dans le même ouvrage, Georges Bélanger, "L'Institut francoontarien (IFO)», pp. 129-144.

${ }^{19}$ Parmi les productions récentes les plus significatives, mentionnons l'ouvrage historique dirigé par Cornelius Jaenen, Les Franco-Ontariens ([Ottawa], Ontario Historical Studies Series / Presses de l'Université d'Ottawa. [c1993], vili-443 p.), et aussi ceux de Roger Bernard, De 
dizaine d'années, le projet d'un Dictionnaire des écrits de l'Ontario français (DÉOF) a aussi amené les chercheurs à définir les limites culturelles de l'Ontario français et à réclamer sa part de l'héritage du Canada français $^{20}$.

Les sociologues furent les premiers à s'intéresser à la question de l'identité franco-ontarienne, question posée carrément dès 1978 par Danielle Juteau-Lee dans un article traitant de la transition de «'Ontario francophone» vers une nouvelle «identité culturelle et identité structurelle». L'année suivante, elle signait avec Jean Lapointe un chapitre sur «l'émergence des Franco-Ontariens", texte repris quatre ans plus tard sous un nouveau titre très révélateur de certaines hésitations: «From French Canadians to Franco-Ontarians and Ontarois». Juteau-Lee avait déjà posé ces questions en 1981, dans un article intitulé: «Français d'Amérique, Canadiens, Canadiens français, Franco-Ontariens, Ontarois: qui sommesnous? $»^{21}$. En fait, ce sont les sociologues qui ont le

Québécois à Ontarois. La communauté franco-ontarienne ([Hearst], Le Nordir, [c1988], 185 p.), de Brigitte Bureau, Un Passeport vers la liberté. Les Caisses populaires de l'Ontario de 1912 d 1992 ([Ottawa], Le Mouvement des Caisses Populaires de l'Ontario, [1992], 330 p.), d'Émilien Lamirande, Elisabeth Bruyère (1818-1876). Fondatrice des Sœurs de la Charité d'Ottawa (Sœurs Grises) ([Montréal], Bellarmin, [c 1993], 802 p.), de François Paré, Les Littératures de l'exiguité ([Hearst], Le Nordir, "Essais", 1992, 175 p.) et de Serge Wagner, Analphabétisme de minorité et alphabétisation d'affirmation nationale d propos de l'Ontario français. Volume I: Synthese théorique et historique ([Toronto, Ministère de l'Éducation], 1991, xil-506 p.). On pourrait facilement allonger cette liste.

20 Voir à ce sujet Gaétan Gervais, "Le Dictionnaire des écrits de l'Ontario français», dans Revue d'histoire littéraire du Québec et du Canada français, $n^{\circ}$ 8, 1984, pp. 249-252; Gaétan Gervais et JeanPierre Pichette, «Le Dictionnaire des écrits de l'Ontario français», dans Vie française, vol. $41, \mathrm{n}^{\circ} 1,1989$, pp. 47-53.

${ }^{21}$ Danielle Juteau-Lee et Jean Lapointe, "The Emergence of FrancoOntarians: New Identity, New Boundaries», dans Jean L. Elliott (dir.), 
plus souvent posé cette question de «l'identité». On peut ajouter à la liste ci-dessus, les travaux de Raymond Breton ${ }^{22}$, de Roger Bernard ${ }^{23}$ et de René Guindon ${ }^{24}$. Ajoutons aussi les travaux récents de

Two Nations, Many Cultures. Ethnic Groups in Canada (Scarborough, Prentice-Hall, [c1979], xili-395 p.), pp. 99-113; Danielle Juteau-Lee, «From French Canadians to Franco-Ontarians and Ontarois: New Boundarles, New Identities", dans Jean L. Elliott (dir.), Two Nations. Many Cultures: Ethnic Groups in Canada ( $2^{\mathrm{e}}$ édition, Scarborough, Prentice Hall, 1983), pp. 173-186; Danielle Juteau-Lee, "Français d'Amérique, Canadiens, Canadiens français, Franco-Ontariens, Ontarois: qui sommes-nous», dans Pluriel, 24, 1980,pp. 21-42; Danielle Juteau-Lee, «Visions partielles, visions partiales: visions minoritaires en sociologie», dans Sociologie et Sociétés, 13(2), 1981, pp. 33-47; Danielle Juteau-Lee, «The Franco-Ontarian Collectivity: Material and Symbolic Dimensions of Its Minority Status», dans Raymond Breton et Pierre Savard (dir.), The Quebec and Acadian Diaspora (Toronto, Multicultural History Society of Ontario, 1982, xi-199 p.), pp. 167182; Danielle Juteau-Lee, "La Production de l'ethnicité ou la part réelle de l'idéel», dans Sociologie et Sociétés, 15(2), 1983, pp. 39-54; Danielle Juteau et Lise Séguin-Kimpton, «La Collectivité francoontarienne: structuration d'un espace symbolique et politique», dans Cornelius Jaenen (dir.), Les Franco-Ontariens ([Ottawa], Ontario Historical Studies Series / Presses de l'Université d'Ottawa. [c1993], vill-443 p.), pp. 265-304.

${ }^{22}$ Raymond Breton, Jeffrey G. Reitz et Victor Valentine, Les Frontières culturelles et la cohésion du Canada (Montréal, Institut de recherches politiques, [c1981]), xx-476 p.; Raymond Breton, "Institutional Completeness of ethnic communities and personal relations of immigrants", dans American Journal of Sociology, 70(2), septembre 1964, pp. 193-205 et dans Bernard R. Blishen et al. (dir.), Canadian Society: Sociological Perspectives (Abridged Edition, Toronto, Macmillan, 1971), pp. 51-68.

${ }^{23}$ Roger Bernard, «L'Ontario français: pratiques ethniques et théories sociologiques», dans Revue de l'Université d'Ottawa, 55(2), avril-juin 1985, pp. 137-150; Roger Bernard, De Québécois à Ontarois. La communauté franco-ontarienne (Hearst, Le Nordir, 1988), 185 p.; Roger Bernard, "Culture et identité franco-ontariennes», dans Jean-Pierre Pichette (dir.), L'Euvre de Germain Lemieux, s.j. Bilan de l'ethnologie en Ontario français. Actes du colloque tenu d l'Université de Sudbury les 31 octobre, $1^{\text {er }}$ et 2 novembre 1991 (Sudbury, Centre franco-ontarien de folklore et Prise de Parole, "Ancrages», 1993, 529 p.), pp. 449-462. ${ }^{24}$ René Guindon, "Consolider son identité par l'égalité et l'autonomie», dans Ajustons nos violons. Concertation 83. Développement global. Document de réflexion ([Ottawa, Association canadienne-française 
David Welch sur l'identité des Canadiens-Français par l'école, au XIX $\mathrm{X}^{\mathrm{e}}$ siècle ${ }^{25}$, et de Serge Wagner, qui prend l'analphabétisme comme caractéristique propre d'une société minoritaire ${ }^{26}$.

Signe des temps, la nouvelle Revue du NouvelOntario, créée en 1978, consacrait son premier numéro aux «Franco-Ontariens à l'heure de l'indépendance", indiquant bien que les chercheurs de l'Institut franco-ontarien n'avaient qu'un œil sur l'Ontario français, l'autre surveillant les activités au Québec. Pierre Savard y publiait un article intitulé «De la difficulté d'être Franco-Ontarien ${ }^{27} \%$. Plus tard, en 1981, la Revue consacra son troisième numéro à une collection de textes sur «les idéologies de l'Ontario français»; la deuxième section du numéro se coiffait du titre «Franco-Ontarien ou Canadien français?» et comprenait des textes du sénateur Hurtubise («Les Canadiens français et le Nouvel-Ontario», 1939) et de Victor Barrette (Moi, Franco-Ontarien, 1947); la troisième partie s'appelait «La recherche d'une identité».

À la même époque, le ministère de l'Éducation décidait de permettre l'enseignement de l'histoire de l'Ontario français et publiait à cette fin un outil péda-

de l'Ontario, 1983]), pp. 1-12 (première section).

${ }_{25}$ Voir son récent article a ce sujet: David Welch, «Early FrancoOntarian Schooling as a Reflection and Creator of Community Identity", dans Ontario History, 85(4), décembre 1993, pp. 321-347.

${ }^{26}$ Voir en particulier le chapitre intitulé "Communauté ou minorité franco-ontarienne?». Chapitre II de Serge Wagner, Analphabétisme de minorité et alphabétisation d'affirmation nationale d̀ propos de l'Ontario français. Volume I: Synthese théorique et historique ([Toronto, MInistère de l'Éducation], 1991, xil-506 p.), p. 75-159.

${ }^{27}$ Pierre Savard, «De la difficulté d'être Franco-Ontarien», dans Revue du Nouvel-Ontario, 1, 1978, p. 11-22. 
gogique $^{28}$, ce qui accréditait l'idée d'une "identité franco-ontarienne». À l'université d'Ottawa, Pierre Savard animait un groupe appelé DOPELFO qui publia plusieurs manuels utiles sur l'histoire francoontarienne ${ }^{29}$. Mais chez les historiens, il y a eu peu d'examen de cette question de l'identité. Le seul historien qui ait adopté cette terminologie de «l'identité franco-ontarienne», c'est Chad Gaffield pour la traduction française de son livre; mais l'ouvrage, portant avant tout sur la fin du XIX ${ }^{e}$ siècle, traite bien peu d'identité, en dehors du titre ${ }^{30}$. En histoire religieuse, il est intéressant de noter qu'une communauté religieuse a récemment associé sa propre histoire au développement des Franco-Ontariens ${ }^{31}$. Dans la perspective du Québec, Marcel Martel s'est aussi penché sur cette question où il a vu un passage

${ }^{28}$ Explorations et enracinements français en Ontario, 1610-1978. Esquisse historique et ressources documentaires [Toronto, Ministère de l'Éducation, 1981J, $160 \mathrm{p}$.

${ }^{29}$ Les ouvrages du projet DOPELFO ont été publtés: Robert Choquette, L'Ontario français, historique (Montréal, Études Vivantes, «L'Ontario français», 1980, viii-272 p.); Jacques Grimard, L'Ontario français par l'image (Montréal, Études Vivantes, «L'Ontario français», 1981 , x-259 p.); Jacques Grimard et Gaétan Vallières, Travailleurs et gens d'affaires canadiens-français en Ontario (Montréal, Études Vivantes, «L'Ontario français», 1986, 231 p.); Gaétan Vallières, L'Ontario français par les documents (Montréal, Études Vivantes, "L'Ontario français", 1980, xiv-280 p.); Gaétan Vallières et Marcien Villemure, Atlas de l'Ontario français (Montréal, Études Vivantes, «L'Ontario français», 1981, 68 p.); André Lapierre, Toponymie française en Ontario (Montréal, Études Vivantes, "L'Ontario françals», 1981 , vii-120 p.).

${ }^{30}$ Chad Gaffield, Aux origines de l'identité franco-ontarienne. Education, culture, économie, traduction de Gilles Hénault avec la collaboration de Lise Demers, [Ottawa], Presses de l'Université d'Ottawa, [c1993], 284 p. Titre original, en anglais: Language, Schooling, and Cultural Conflict. The origins of the French-Language Controversy in Ontario, Kingston/Montréal, McGill-Queen's University Press, [c 1987], xviii-249 p.

${ }^{31}$ Hélène Bériault, Les Sours de Sainte-Croix dans la montée avec les Franco-Ontariens. Province Notre-Dame-de-Lourdes. Préface d'Alice 
de «la certitude au doute ${ }^{32}$ ». Que les historiens contribuent aux définitions identitaires, c'est une pratique qui se retrouve chez presque tous les peuples et qu'on a vue à l'œuvre au Québec où toute l'histoire a été recrée à la lumière d'une invention asymétrique, le Québec-Canada. Ce travail de redéfinition et de réécriture du passé est illustré parfaitement par l'ouvrage récent de Fernand Dumont ${ }^{33}$.

\section{Enfin, les politicologues tels Denis Gratton ${ }^{34}$ et les} essayistes tels Jean Ethier-Blais ${ }^{35}$, René Dionne ${ }^{36}$, et François Paré, auteur d'une récente étude sur «l'ins-

Groulx, Cornwall, Sœurs de Sainte-Croix, [c1989], viii-447 p.

${ }^{32}$ Marcel Martel, «De la certitude au doute: l'identité canadiennefrançaise de l'Ontario de 1937 à 1967», dans Linda Cardinal (dir.), Une langue qui pense. La recherche en milieu minoritaire francophone au Canada ([Ottawa], Les Presses de l'Université d'Ottawa), "Actexpress", [c1993], 183 p.), pp. 65-76.

${ }^{33}$ Fernand Dumont, Genèse de la société québécoise, s.l., Boréal, [c1993], 397 p. On peut lire, à la page 57: "Car l'origine, ce n'est pas uniquement ce que reconstitue la science historique. C'est le moment privilégié auquel se reporte la recherche de l'identité collective. L'origine est problématique comme l'identité elle-même. Par-delà la critique des documents à laquelle se livre l'historien, elle relève d'une inquiétude quant au destin d'une société. C'est pourquoi une interrogation dominera toutes les autres: l'origine, était-ce la promesse d'un avenir?» Sur ce développement de l'historiographie néo-nationaliste, voir Jean Lamarre, Le Devenir..., op. cit., et Jacques Mathieu, «L'Identité québécoise: l'approche de l'historien", dans Approches de l'identité québécoise (Québec, Université Laval (CÉLAT), "Cahiers du CÉLAT» 3, 1985), pp. 1-31.

${ }^{34}$ Denis Gratton, Production de la différence: le cas ontarois. Thèse de doctorat, Université Laval, 1990, 255 p.

${ }^{35}$ Jean Éthier-Blais, "L'Être minoritaire», dans Liberté, 4, mars 1962 , pp. 84-89. Aussi «L'Être français minoritaire», dans Relations, en deux parties, «1. Le resserrement de l'espace», vol. $38, \mathrm{n}^{\circ} 443$, décembre 1978 , pp. 325-326 et «2. Arrêter l'érosion de la culture française», vol. $39, \mathrm{n}^{\circ} 244$, janvier 1979, p. 20.

${ }^{36}$ René Dionne, "La Littérature franco-ontarienne: esquisse historique», dans Cornelius Jaenen (dir.), Les Franco-Ontariens ([Ottawa], Ontario Historical Studies Series / Presses de l'Université d'Ottawa. [c1993], viil-443 p.), pp. 341-417; René Dionne, «Littérature outaouaise et franco-ontarienne», dans Bulletin du Centre de recherche en civilisa- 
titution littéraire franco-ontarienne ${ }^{37}{ }$, ont aussi examiné la question identitaire franco-ontarienne. Parmi les interrogations soutenues, on peut aussi citer les travaux de Fernand Dorais qui a écrit des textes percutants, et indignés, sur la situation minoritaire et sur le bilinguisme assimilateur ${ }^{38}$. Sur les problèmes de l'identité, les linguistes, avec leur préoccupation

tion canadienne-française, $\mathrm{n}^{\circ} 16$, avril 1978, pp. 1-4; René Dionne, «Pourquol étudier la littérature franco-ontarienne?», dans Bulletin du Centre de recherche en civilisation canadienne-française, $n^{\circ} 24$, avril 1982, pp. 1-4. Aussi dans Plerre Savard (dir.), Aspects de la civilisation canadienne-française (Ottawa, Éditions de l'Université d'Ottawa, «Cahiers du Centre de recherche en civilisation canadienne-française» 22, 1983, xi-341 p.), pp. 137-140; René Dionne, "De la littérature française à la littérature canadienne-française», dans René Dionne, Le Québécois et sa littérature (Sherbrooke, Éditions Naaman, 1984, 464 p.), pp. 31-46.

${ }^{37}$ François Paré, «L'Institution littéraire franco-ontarienne et son rapport à la construction identitaire des Franco-Ontariens», dans Jocelyn Létourneau (dir.), La Question identitaire au Canada francophone. Récits, parcours, enjeux, hors-lieux (Sainte-Foy, Presses de l'Université Laval, "Culture française d'Amérique», 1994, xvi-292 p.), pp. 4562. Voir aussi, du même auteur, Les Littératures de l'exiguïté ([Hearst], Le Nordir, "Essais», 1992, 175 p.), en y ajoutant l'entrevue que l'auteur donnait, «Un nouveau savoir littéraire. Entretien avec François Paré», Liaison, 76, 15 mars 1994, pp. 16-18). Enfin, voir aussi François Paré, "L'Guvre narrative de Michelle Le Normand", dans Cultures du Canada français 5, automne 1988, pp. 207-213 et François Paré, "Solxante-dix ans de nouvelle franco-ontarienne: Turcot, Thério, Poliquin», dans Agnès Whitfield et Jacques Cotnam (dir.), La Nouvelle: écriture(s) et lecture(s) ([Toronto], Éditions du GREF, "Dont Actes" $10 /$ [Montréal], XYZ Éditeur, «Documents», [c1993], 226 p.), pp. 157-165.

${ }^{38}$ Fernand Dorais, «Représenter les francophones en cette province. De la culture à l'acculturation», dans Fernand Dorais, Entre Montréal... et Sudbury. Pré-textes pour une francophonie ontarienne. Essais ([Sudbury], Prise de Parole, 1984, 165 p.), pp. 83-91; Fernand Dorals, "Minorité, autonomie et dépendance: vues d'un littéraire», dans $\mathrm{Re}$ vue du Nouvel-Ontario, 8, 1987, pp. 49-61 et dans Fernand Dorais, Témoins d'errances en Ontario français. Réflexions venues de l'amer ([Hearst], Le Nordir, «Essai», [c1990], 149 p.), pp. 133-149; Fernand Dorais, "Le Minoritaire: approches méthodologiques", dans Revue du Nouvel-Ontario, 11, 1989, pp. 193-196. 
des questions de l'assimilation, ont aussi apporté plusieurs études, comme Benoît Cazabon qui a publié en 1989, dans la Revue du Nouvel-Ontario, un numéro complet sur les questions de l'identité ${ }^{39}$. Aussi la question de l'identité a été souvent liée aux problèmes de l'assimilation, voire au bilinguisme comme caractéristique fondamentale du minoritaire ${ }^{40}$ comme l'ont exposé Roger Bernard et Fernand Dorais. En géographie, Anne Gilbert a posé le problème identitaire en termes de région ${ }^{41}$. Enfin des réflexions sont venues du monde de l'enseignement ${ }^{42}$.

Cette préoccupation au sujet de la question de l'identité est une activité de chefs de file, d'universitaires et d'artistes. Dans la population française de l'Ontario, on continue comme avant à s'appeler

${ }^{39}$ Dans ce numéro de la Revue, voir les articles de Jean-Yves Cayen, «Le Minoritaire», Revue du Nouvel-Ontario, 11, 1989, p. 199; Benoît Cazabon, "Qu'est-ce qu'un minoritaire?», pp. 173-174; Benoît Cazabon, «Qui est minoritaire?» pp. 211-212; Donald Dennie, «Le Minoritaire franco-ontarien», pp. 181-183; François Ribordy, "Comment devenir minoritaire?», pp. 189-191; Gaétan Gervais, «Le Minoritaire culturel», 11, 1989, pp. 177-179. Voir aussi Simon Laflamme, «Éléments pour une analyse de la conscience franco-ontarienne», pp. 35-46; Denis Lapalme, "Le Minoritaire francoontarien", pp. 201-209; Jean Lapointe, «Vle culturelle et institutions autonomes: minorités culturelles et institutions», pp. 97-102.

${ }^{40}$ Rodrigue Landry et Réal Allard, «Bilinguisme additif, bilinguisme soustractif et identité ethnolinguistique», dans Recherches sociographiques, 15(2-3), 1984, pp. 337-358; G. Frank Vallee, «Regionalism and Ethnicity: The French-Canadian Case», dans L. Jean Elliott, Minority Canadians 2: Immigrant Groups (Scarborough, Prentice-Hall, 1971), pp. 151-159 (ou 153-167).

${ }^{41}$ Anne Gilbert, "L'Ontario français comme région: un regard non assimilationniste sur une minorité, son espace et ses réseaux», dans Cahiers de géographie du Québec, vol. 35, n 96, décembre 1991, pp. 501-512.

42 Denise Paquette-Frenette, "Réflexions en vrac...» [Au sujet du minoritaire franco-ontarien], dans Revue du Nouvel-Ontario, 11, 1989, pp. 185-187. On a aussi publié une collection de documents, À la recherche d'une identité franco-ontarienne (Compilés par Bernard Clavel, 
"canadien-français», sans arrière-pensée. La population "canadienne-française de l'Ontario» ou «franco-ontarienne» ne ressent pas autant qu'une partie de ses élites, le besoin d'une nouvelle définition de ce qu'elle est. Ne faudrait-il pas aussi s'interroger sur l'origine de tous ces chercheurs qui s'inquiètent de «l'identité franco-ontarienne» et qui le font d'un point de vue québécois?

Au fait, deux questions différentes se posent: existet-il une chose nouvelle qui s'appelle «l'identité francoontarienne», et le mot pour la décrire est-il nouveau ou ancien? Car, à côté du débat de fond, il existe d'abord un débat de mots. Une orthodoxie rigide a banni le mot "canadien-français" de la place publique. Qui a déclaré cet anathème, dans les hauts lieux du savoir intellectuel où s'exerce le contrôle du langage? Cette décision dépendait des fonctionnaires, des politiciens, des journalistes, des éducateurs, des intellectuels, en somme de ceux qu'on appelle en sociologie les "définisseurs de situation», maîtres du vocabulaire officiel. Réduit à un terme de mépris, le mot «canadien-français» a effectivement disparu du vocabulaire, non seulement au Québec, mais partout au Canada ${ }^{43}$. Même les papillons du Bon Dieu, mutés en "papillons du Québec» et conscrits dans les armées de l'affirmation québécoise, ont rejoint à leur

Maurice Grenier, Michel L'Écuyer et Gérald Samson, Toronto, Champlain / Montréal, Éditions Guérin, 1984: Fascicule 1: La culture - notre culture (xv-247 p.). Fascicule 2: La question scolaire (xv-214 p.). Fascicule 3: Le jeu des nombres (xili-146 p.).

${ }^{43}$ Voir par exemple Jean Bouthillette, Le Canadien français et son double. Essai, [Montréal], L'Hexagone, [c1989], 99 p., où il est question de "dépersonnalisation", de "culpabilité" et de "reconquête", d' «humiliation», de "solitude», de "dépossession», de "servitude», de "souffrance», de "décolonisation». Yves Couture, cité plus haut, met bien en lumière le caractère millénariste du néo-nationalisme. L' «homme nouveau», dans cette nouvelle foi politique, s'appelle «Qué- 
insu les bataillons formés par les «tomates du Québec», les "médailles olympiques du Québec», les "poissons du Québec», les «soldats québécois en Bosnie», le "commerce international du Québec», les "vins du Québec», les "veaux du Québec», et mille autres expressions ejusdem farince, toutes entendues au réseau national, c'est-à-dire canadien, de Radio-Canada, et toutes appelées à renforcer, dans les cœurs et dans le langage, la primauté de la "chose québécoise ${ }^{44} \gg$.

Comment ne pas s'interroger sur la complicité de fait qui a permis cette élimination du mot «canadienfrançais» dans les grands organismes qui ont le pouvoir d'influencer l'usage des mots? Trois grandes influences sont faciles à identifier. La première fut celle des mouvements néo-nationalistes québécois, qui ont développé le tic de ruer chaque fois que le mot Canada est prononcé: adieu Radio-Canada, bonjour SRC! Ils ont, grâce à leur contrôle de la presse, écrite et parlée, à leur emprise sur l'édition et sur le système scolaire, écarté systématiquement le mot "canadien-français». La deuxième grande influence qui a joué fut celle de Radio-Canada qui, malgré

bécois», et doit remplacer l'«homme ancien" qu'était le CanadienFrançais. Nous entrons ici dans le domaine de la religion, où les arguments n'ont pas de réponse. Désormais, ce n'est plus l'Église, mais l'État, plus exactement l'État-Nation, qui doit assurer le salut du peuple élu.

${ }^{44}$ L'idée que l'expérience d'une nation est unique, ou «exceptionnelle», court à travers l'historiographie de plusieurs peuples, développée par les romantiques allemands du $\mathrm{XIX}^{e}$ siècle puis maintenue avec ardeur par des générations d'historiens américains, sans oublier le statut de "peuple élu» que plusieurs autres ont voulu s'attribuer. Au Canada, la notion de «société distincte» réclamée par le Québec (plutôt que par le Canada français) s'inscrit dans cette tradition. Aux ÉtatsUnis, la question d'«exceptionalisme" a été débattue récemment: Ian Tyrrell, "American Exceptionalism in an Age of International History», dans American Historical Review, 96(4), octobre 1991, pp. 1031-1055. 
son mandat, n'a jamais reflété convenablement l'ensemble du Canada, surtout le réseau de la télévision. La société d'État a systématiquement remplacé le mot "canadien-français» par le terme "québécois», et, quand la chose devenait intenable, elle recourait au détestable "francophone», le plus souvent aux «francophones-hors-Québec», voire aux «francophones du Canada anglais». Ce qui nous amène à la troisième grande influence, le Secrétariat d'État, devenu récemment Patrimoine canadien ${ }^{45}$, qui, à cause de ses politiques «linguistiques», a contribué largement à imposer le mot "francophone» qu'on sert maintenant à toutes les sauces, en passant par les "édifices francophones», les "comités francophones», les «sourds-muets francophones», les «danses francophones» et la «culture francophone». Tout cela pour dire que les mots ne sont pas innocents.

Pendant vingt ans, on passa donc de CanadienFrançais à Francophone, puis à Francophonehors-Québec, à Ontarois, avant de revenir à Franco-Ontarien, qui a toujours été synonyme de "canadien-français de l'Ontario". Ce terme semble aujourd'hui définitivement établi, puisqu'en juin 1991, lors des grandes assises baptisées «Sommet de la francophonie ontarienne», une décision unanime adopta l'expression "communauté francoontarienne» pour décrire la population de langue et de culture françaises vivant en Ontario, y compris les diverses communautés culturelles franco-ontariennes qui font maintenant partie de l'Ontario français («communauté franco-ontarienne dans toute sa diversité» précisait la définition) ${ }^{46}$. L'emploi du

${ }^{45}$ À ne pas confondre avec Héritage Canada, un organisme non gouvernemental et privé, voué à la protection du patrimoine.

${ }^{46}$ Le produit de ce sommet fut le «Plan de développement global de la 
terme "franco-ontarien" est ancien, dans le sens de "Canadien-Français de l'Ontario", comme on peut le voir dans les pages du journal Le Droit dans les années 1920 ou chez le chanoine Lionel Groulx qui, dans son Enseignement français au Canada. Tome II: Les Écoles des minorités, publia un chapitre sur les "écoles franco-ontariennes ${ }^{47}$ ». Aujourd'hui, toutefois, le mot se charge de nouveaux contenus.

\section{V - La NouvelLe direction en Ontario français}

Énoncée à la fin du XIX'e siècle par l'historien américain Frederick Jackson Turner, la "thèse de la frontière» servit pendant des générations à l'interprétation du développement national des États-Unis. Elle mettait l'accent, dans la formation du caractère américain, sur l'influence de la "frontière», cette région ouverte située aux marges de la société organisée et attirant des individus possédant un esprit d'entreprise, une indépendance de tempérament, un sens de l'entraide, le goût de la liberté, une pratique de la démocratie, autant de caractéristiques qui forgèrent le caractère américain. Mais cette description ne semblait pas répondre adéquatement à la situation canadienne et au développement des différentes régions du pays. Ici, l'autorité vint des centres politiques, économiques et sociaux qui contrôlèrent le développement des nouvelles régions. Ainsi, la thèse du "métropolitanisme», proposée en 1954 par l'histo-

communauté franco-ontarienne 1992-1997".

${ }^{47}$ Lionel Groulx, L'Enseignement français au Canada, 2 volumes: volume I: Dans le Québec, Montréal, Granger Frères, "Documents historiques» 1933, 327 p., surtout le volume II: Les Écoles des minorités (Montréal, Granger Frères, 1933, «Études historiques», 1933, 271 p.). Dans le deuxième tome, voir le chapitre II: «Les Écoles francoontariennes», II, pp. 194-239. 
rien canadien J. M. S. Careless, prenait le contre-pied de la "thèse de la frontière» en mettant plutôt l'accent sur le rôle que jouèrent les métropoles dans le développement économique et social du pays.

En étendant l'application de ce concept de métropolitanisme à l'analyse du Canada français, surtout du point de vue culturel, on arrive à jeter un éclairage neuf sur les "métropoles du Canada français» d'une part, et sur la place d'Ottawa en Ontario français d'autre part. Pour la période plus récente, cette approche fera mieux comprendre une transformation en cours: le déclin du rôle d'Ottawa dans le leadership franco-ontarien et la montée de Sudbury et surtout de Toronto.

Au sommet du monde français, la métropole culturelle est depuis longtemps Paris, mais dans les différentes régions de l'aire culturelle française, des métropoles régionales exercent une influence locale (Montréal, Québec et Ottawa). À un niveau inférieur, d'autres villes jouissent d'une influence plus limitée. À l'époque du Canada français, avant les années soixante, trois villes canadiennes jouirent de ce rôle de «métropoles régionales»: Québec, Montréal et Ottawa. Ces métropoles régionales tinrent un rôle important parce qu'elles décidaient ce qui se publierait, ce qui se lirait, ce qui serait jugé bon et beau, ce qui serait vu ou entendu. Ces villes possédaient les grandes institutions culturelles d'enseignement (universités, collèges), de diffusion (journaux, maisons d'édition, revues), de regroupement (sièges sociaux des grandes associations), de vie culturelle (théâtre, musique, peinture, arts). Entre ces trois capitales régionales, les élites rivalisaient mais circulaient sans trop de difficulté parce qu'elles 
avaient le fort sentiment d'appartenir à une même nation canadienne-française. Il importait assez peu, alors, qu'on soit né dans telle province ou dans telle région, pourvu qu'on fût catholique et français. Ainsi, l'élite canadienne-française d'Ottawa se recrutait souvent à l'extérieur, attirée par le gouvernement fédéral et les autres activités politiques et religieuses de la capitale du Canada.

Étant donné le prestige de cette élite, il était normal qu'elle dominât la vie culturelle de l'Ontario français, bien qu'une région comme Sudbury se rattachât davantage, dans le domaine culturel, à Montréal qu'à Ottawa. En fait, le leadership francoontarien, jusqu'à récemment, eut ses plus fortes assises à Ottawa et dans les institutions comme le fonctionnariat fédéral, le journal Le Droit, la communauté des oblats, le clergé canadien-français et tous les sièges provinciaux des organismes francoontariens. Au XIX ${ }^{e}$ siècle, lorsque l'Institut canadienfrançais d'Ottawa rayonnait par ses activités culturelles, les hauts fonctionnaires et les hommes politiques en vue devenaient naturellement des membres actifs de la communauté canadienne-française d'Ottawa, comme ce fut le cas pour les sénateurs Pascal Poirier (du Nouveau-Brunswick) ou Philippe Landry (du Québec) et pour les hauts fonctionnaires comme Joseph-Charles Taché, Benjamin Sulte ou Cyprien Tanguay. L'oblat Georges Simard, en 1937, en affirmait autant quand il indiquait, à la veille du Congrès de la langue française, que «le mouvement patriotique de notre siècle a commencé, pour une grande part, au cœur d'Ottawa ${ }^{48}$ \%.

\footnotetext{
${ }^{48}$ Voici la suite du texte: "C'était en 1887 . Un jeune religieux, ardent comme sa race, enseignait à notre université. Il lui vint l'idée de fonder
} 
L'émergence d'une nouvelle «identité francoontarienne», la rupture du Canada français, l'éloignement grandissant entre les Franco-Ontariens et les Québécois, «l'ontarianisation» de la vie francoontarienne, la fin du leadership clérical qui a toujours eu à Ottawa des assises très fortes, enfin les nouvelles conditions faites à sa minorité française par le gouvernement ontarien, tous ces facteurs ont donné une nouvelle direction à la société francoontarienne. En fait, depuis vingt ans, il se produit en Ontario français un déplacement du centre de gravité politique vers Sudbury et vers Toronto.

Récemment, lors d'une émission culturelle diffusée à La Chaîne française de TVOntario, un débat a surgi entre Paulette Gagnon, du Théâtre du NouvelOntario, et René Dionne, professeur de lettres à l'Université d'Ottawa. Pour la première, la création littéraire franco-ontarienne avait commencé dans les années soixante-dix à Sudbury, dans la mouvance

une Société des Débats français. Ce jour-là, le Père Adélard Langevin, le futur archevêque de Saint-Boniface et l'apôtre mitré du patriotisme dans la province de Québec, suscitait le risorgimento canadienfrançais dans l'Ontario. Peu après, en 1901, le Père Henri Gervais, préfet des études, revigorait toute l'organisation française de sa maison, malgré le grand nombre des élèves irlandais et le faible appui d'une portion notable du public français. En 1910, un autre maître, l'un des plus brillants parmi les Oblats d'Ottawa, le Père Émile David, montait, avec quelques laïques intelligents et décidés, le premier congrès des pères de famille franco-ontariens. Immédiatement suivit l'Association d'Éducation. Puis, en 1913, parut Le Droit. Si ces dernières créations et leurs nombreuses initiatives eussent été possibles sans l'attitude et les victoires persistantes de l'Université, c'est un litige qui semble tranché. Ce qui importe davantage c'est de mentionner que, depuis cinquante ans, les progrès des nôtres n'ont pas ralenti un instant dans l'Ontario. Et cela grâce au régime de notre État fédératif", dans Georges Simard, Principes et faits en histoire. État idéal et État canadien. Et séparatisme [Ottawa, Université d'Ottawa], 29 p. Ce texte, publié sous forme de brochure, a d'abord paru dans une livraison de la Revue de l'Université d'Ottawa, en juillet-septembre 1937. 
de Prise de parole, tandis que le second insistait sur les antécédents lointains de la vie culturelle francoontarienne, notamment à Ottawa où on trouve de nombreux écrivains dès le dernier tiers du siècle dernier. On donnera raison à l'un ou à l'autre selon qu'on perçoit la «culture franco-ontarienne" comme une chose nouvelle ou comme la continuité de la culture canadienne-française. De toute évidence, il existe un problème de définition touchant le contenu du terme "franco-ontarien». Car il a existé à Ottawa, déjà dans le dernier tiers du XIX $\mathrm{XIècle}^{\mathrm{e}}$ une communauté littéraire qui travaillait dans la fonction publique fédérale et qui se regroupait autour de l'Institut canadien-français d'Ottawa. Ces écrivains appartiennent à l'histoire culturelle de l'Ontario français, en tout cas à l'histoire du Canada français en Ontario, non à la récente "culture québécoise».

Cette discussion permet cependant d'éclairer une autre transformation de la société franco-ontarienne. Alors que le leadership franco-ontarien, jusque dans les années soixante, s'est trouvé massivement réuni à Ottawa (institutions d'enseignement, communautés religieuses, sièges des organismes provinciaux, proximité du Québec), la direction de l'Ontario français lui échappe toujours plus. Les élites d'Ottawa perdent graduellement leur influence sur la vie francoontarienne, n'ayant pas réussi à suivre le vaste mouvement qui oriente désormais les actions non seulement vers Sudbury, la rivale historique d'Ottawa, mais vers Toronto, appelé à jouer un plus grand rôle, même culturel, en Ontario français. Dans cette perspective, la décision de Radio-Canada de fermer le seul poste entièrement franco-ontarien de sa chaîne de télévision, à Toronto, est incompréhensible: com- 
ment s'expliquer l'absence d'un poste de télévision française dans la plus grande ville du Canada?

En effet, les années soixante ont produit une crise qui a modifié en permanence l'ancien rôle de capitale régionale du Canada français rempli par les élites d'Ottawa. Dans la nouvelle conjoncture, les élites actuelles d'Ottawa sont divisées entre des allégeances internationales, québécoises et francoontariennes. Quel est le "nous" qui sous-tend les discours des professeurs de l'université d'Ottawa, des annonceurs de Radio-Canada ou des fonctionnaires de Patrimoine canadien?

Cette aliénation des élites d'Ottawa et leur absence de la vie franco-ontarienne coûtent très cher à l'Ontario français, au point de vue culturel, et expliquent que, de plus en plus, les organisations provinciales recrutent dans le Nord et dans le Sud leurs membres et donc leurs chefs. Indécises sur leurs attaches ontariennes, les élites d'Ottawa se marginalisent par rapport à l'évolution de l'Ontario français. La question de l'université franco-ontarienne met parfaitement en évidence ces tiraillements.

Pour preuve récente de ce déplacement inexorable du leadership franco-ontarien vers Toronto, il suffit de rappeler qu'en 1993, l'ACFO prenait la décision historique de déménager son siège social d'Ottawa à Toronto. Il ne s'agit pas d'un vain geste symbolique, mais d'une action avantageuse au point de vue politique. Le leadership franco-ontarien s'est joué entre Ottawa et Toronto, et celui-ci est en train de l'emporter. 


\section{Conclusion}

Qu'est-ce que l'identité, sinon la forte adhésion d'une personne à un groupe où elle reconnaît des valeurs jugées assez importantes pour l'emporter sur les autres? Le nombre de nos appartenances étant élevé, il est facile de voir que selon les époques ou les circonstances, telle identité (familiale, religieuse, politique, géographique) paraîtra plus importante que les autres. Même à l'intérieur d'une vie individuelle, l'importance relative des appartenances peut changer. Parler uniquement de "l'identité franco-ontarienne", ce serait donc implicitement affirmer que l'appartenance à la communauté franco-ontarienne compte plus, dans la vie de ses membres, que toute autre appartenance. Car on peut en même temps être canadien, ontarien, catholique, ouvrier, collectionneur de timbres.

Les sources lointaines de l'Ontario français se trouvent dans l'Empire français du XVIII ${ }^{\mathrm{e}}$ siècle, mais sa principale période de formation correspond au vaste mouvement d'expansion du Canada français dans la deuxième moitié du XIX ${ }^{e}$ siècle. Aujourd'hui, les ponts avec le Québec sont largement coupés et personne ne sait si, ni comment, ils seront reconstruits. La rupture de ces liens culturels avec le Québec explique l'urgence culturelle d'affirmer une nouvelle identité franco-ontarienne.

L'identité d'une communauté se fonde sur une certaine mémoire de son passé, sur une certaine compréhension de son expérience historique. Ainsi, il existe un lien entre l'histoire, telle que l'interprètent les chefs du groupe auquel on s'identifie, et l'identité qu'on veut mettre de l'avant. L'expérience historique résulte d'événements réels, mais le souvenir qu'on 
en garde se prête à bien des interprétations. La part du subjectif est donc importante dans la définition d'une identité, les faits et les événements passés étant sans cesse réinterprétés par les communautés. Ainsi, de nouvelles identités naissent continuellement, émergeant constamment de nouvelles lectures du passé. Combien de groupes, en Amérique du Nord, ont "retrouvé leur identité» depuis trois décennies: les Noirs, les Amérindiens, les femmes, les gais, les Québécois?

La nouvelle «identité franco-ontarienne» est une "construction", mais elle répond à de nouvelles conditions, culturelles et politiques, engendrées par l'éclatement du Canada français. Elle permet d'aborder les difficultés auxquelles est confrontée la minorité canadienne-française de l'Ontario. Justement parce que les identités sont des constructions de l'esprit, elles jouent un rôle central dans la vie des personnes, comme mode d'explication du monde, comme incitation à l'action, comme moyen de mobilisation.

On aurait donc tort de chercher des facteurs objectifs qui définiraient «l'identité franco-ontarienne». En historiens, cherchons plutôt, dans le long terme, le contexte qui explique la naissance, à ce point de l'histoire, d'une nouvelle identité où se trouveront à la fois des points de rupture et des marques de continuité, c'est-à-dire de reproduction culturelle. Mais comment argumenter sérieusement que les exemples de ruptures sont plus nombreux que les faits de reproduction culturelle? En bref, l'Ontario français est le produit de la deuxième crise de l'Amérique française (1960-1995), comme le Canada français est sorti de la première crise (1760-1814). Mais pour bien marquer les continuités, soulignons aussi que 
"l'identité franco-ontarienne», comme «l'identité québécoise», et malgré des ruptures profondes, ne sera jamais que le prolongement de l' «identité canadiennefrançaise», elle-même le prolongement de l'«identité française».

* L'auteur tient à remercier les membres de la Société et aussi Serge Dignard, Rolande Faucher, Guy Gaudreau et Jean-Yves Pelletier, qui ont lu et commenté ce texte. Leurs bons conseils ont permis de l'améliorer, mais les erreurs, toutefois, ne sont imputables qu'à l'auteur. 